\title{
A New Definition Of A Business Model
}

\author{
Nancy J. Niles, Lander University, USA
}

\begin{abstract}
This paper discusses the lack of agreement on the definition of a business model which is a recent addition to management literature since the dot com era. An abbreviated literature review was discussed that emphasizes the different perspectives of business model definitions. There are categories such as auction, subscription, or advertising business models which describe the processes between a buyer and seller (Rappa, 2005). Business models have also been defined in the literature as a system with components (Afuah\&Tucci, 2001) or a method to make money (Weill\&Vitale 2001). They have also been categorized as business to business models or business to consumer models (Haag, 2004) This author has developed a new definition of a business model that focuses on the transaction between the buyer and seller, regardless of whether it is a traditional transaction, an electronic transaction or the type of transaction. The paper has provided six comparisons of the difference between a traditional transaction between a buyer and a seller and an electronic transaction between a buyer and a seller. The direct comparisons of traditional and e-commerce business models illustrate the major component of a business modelthe transaction that occurs between the seller and buyer and that the transaction must be included in the definition of a business model.
\end{abstract}

Keywords: business model definitions, literature review, information technology, e-commerce

\section{INTRODUCTION}

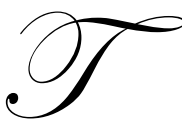

he last 15 years have witnessed the hyper growth of the Internet which, combined with information technology (IT), has created a global and cost-effective platform for businesses to conduct electronic commerce (e-commerce) transactions, which is a paperless exchange of business information on the Internet (Rao,Mett \& Mongue, 2003). E-commerce has enabled customers and entrepreneurs to form instant relationships that would not be possible without information technology. The term business model is a recent addition to the management literature and largely a product of the dot com era (Keen \& Qureshi, 2006). It is used extensively in e-commerce literature and is used in many contexts, but it is difficult to understand what a business model actually is (Timmers, 1999; Hawkins, 2002). The term is defined differently by many authors and there is minimal consensus as to the similar characteristics of business models (Lambert, 2006). This author feels that the term 'business model' can be applied to both traditional business relationships and e-commerce relationships and that business model definitions should focus on the transaction activities that occur between the business and its consumers.

This author purports that e-commerce businesses have used traditional business transaction relationships between businesses and their customers but have developed methods which enable faster transactions to be processed. E-commerce has introduced more rapid seller and consumer transactions that are based on traditional transaction activities between a business and consumer. This paper will discuss direct comparisons between a traditional business relationship and an e-commerce business relationship, illustrating that the difference between the two relationships is the transactional process of the relationship, not the model of the relationship.

\section{ABBREVIATED LITERATURE REVIEW OF THE DEFINITIONS OF BUSINESS MODELS}

Definitions of business models vary. The term 'business model' is a recent addition to management literature. Until the mid-1990's, the term was absent from business theory and strategy. The term has appeared in much e-commerce popular and academic press. Most work on business models is descriptive based on case 
examples, such as eBay, Amazon, and Google. There are typical categories, such as subscription, auction, brokerage or advertising (Rappa, 2005). At this time, there appears to be no general classification of a business model, which means that there is little theoretical basis for business model applications (Keen \& Qureshi, 2006). Timmers (1999) has stated that the business model is the architecture for a business to communicate. Afuah and Tucci (2001) define a business model as a system with components and linkages. Weill and Vitale (2001) categorize a business model as a method to make money. Porter (2001) calls it a loose conception of how a company does business. Hawkins (2002) defines a business model as a description of the relationship between a business and its market. Mahadevan (2000) proposed a three dimensional framework and applied it to an emerging market structure.

The dot com or e-commerce business model was the starting point for successful firms, such as eBay, Amazon and Google. Yet there appears to be little agreement on the classification of these e-commerce business models. Does the term 'business model' accurately describe the transactions of e-commerce activity between buyers and sellers? The author feels that the foundation of e-commerce activity is based on the traditional transactional activities of buyers and sellers. To illustrate the focus of e-commerce business transaction models, this paper will focus on comparing the traditional business transaction models (TBM) with e-commerce business transaction models (eBTM).

Peter Drucker has stated that “...the explosive emergence of the Internet as a major worldwide distribution channel for goods, services, and for managerial and professional jobs profoundly changed economies, markets, and industry structures, consumer behavior, and labor markets" (Drucker 1999). Even though the dot com industry became the dot com debacle in 2000, the concept of e-commerce has remained a staple in how business transactions are conducted. IT has been integrated into our lives and businesses as the normal way of doing business and running our lives. This ability to connect with other people and businesses has dramatically increased the acceleration of the business cycle. Historically, any jump in technology -- ships, railroads, telegraphs, to mobile phones -- has shrunk the globe in space and time and has enabled us to connect more quickly and has reduced the business cycle time (Meyer, 2004). The rapid evolution of technology has revolutionized the way businesses operate in both the corporate and small business sectors. As a result of e-commerce, instant relationships between customers and entrepreneurs have been developed. Businesses have realized the tremendous cost savings of electronic transactions. They can reduce barriers, such as time, geographic location and language (Niles, 2007). Due to the limitations of the paper, the discussion will focus on a comparison between the traditional business transaction model and two main e-commerce business transaction models: business2business (B2B) and business2consumer (B2C) models. A third model, the e-commerce broker model, which can be applied to both B2B and B2C models, will also be discussed.

\section{COMPARISONS OF E-COMMERCE AND TRADITIONAL BUSINESS TRANSACTION MODELS}

\section{Business2Business Transaction Model}

Business2business (B2B) transactions occur when a business establishes consumer relationships with other businesses. Global B2B e-commerce accounts for $97 \%$ of all e-commerce revenues. At the end of 2003, the value of goods and services sold by B2B models has been estimated at $\$ 1.41$ trillion (Hansen, 2003). Companies such as Cysco Systems, Dell Computer, and Intel have been successful users of this e-commerce model (Niles, 2007).

Tables 1 and 2 illustrate the comparison of the traditional B2B purchase as compared to an e-commerce $\mathrm{B} 2 \mathrm{~B}$ purchase. There are seven steps associated with the traditional $\mathrm{B} 2 \mathrm{~B}$ purchase as compared to three steps in the e-commerce B2B transaction model (eB2BTM). The Institute for Supply Management estimated that to purchase a \$35 lamp using a traditional purchase order process, with the time spent on forms completion, it costs a company $\$ 76$ to process the lamp, which means the $\$ 35$ lamp costs the company over $\$ 100$ (www.ism.ws/). 


\begin{tabular}{|ll|}
\hline \multicolumn{1}{|c|}{ TABLE 1: TRADITIONAL BUSINESS2BUSINESS TRANSACTION (B2BT) MODEL } \\
Steps in Business Purchases Lamp from Vendor \\
1. & Business contacts business via telephone or email \\
2. & Business supplier sends catalog of products \\
3. & Business production representatives have physical meeting with other business suppliers to develop relationship \\
p. & Suppliers develop cost estimates for obtaining business \\
5. & Business production representatives discuss proposals with management \\
6. & Contract is developed and approved at all management levels \\
7. & Contract is signed by all parties \\
\hline
\end{tabular}

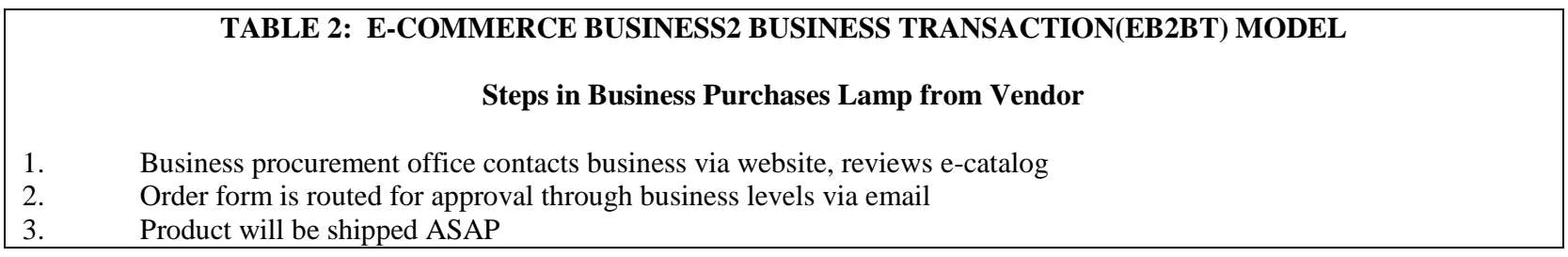

\section{Business Transaction Analysis}

The traditional business2business (B2BT) model transaction takes approximately seven steps to complete and is time and labor intensive. The electronic business2business transaction (eB2BT) model dramatically reduces labor and time with a three-step process that decreases the business cost of processing, thereby increasing the profit margin. The e-commerce model is preferred because it is a more efficient labor process. These two models describe the transactional activities between the seller and consumer. How the transactions are implemented determines the success or profitable relationship between the two parties.

\section{BUSINESS2BUSINESS MARKETPLACES}

$\mathrm{B} 2 \mathrm{~B}$ e-marketplaces represent one of the fastest growing fields in the B2B e-commerce model. These virtual markets bring buyers and sellers together. B2B aggregators or marketplaces are a successful concept that enables businesses to sell different services and products to different businesses. B2B vertical marketplaces focus on providing an opportunity within a certain industry to purchase products. B2B horizontal marketplaces provide an opportunity for businesses in varied industries to purchase office supplies, travel, shipping and financial services (Rappa, 2005).

Haag states that businesses have realized they can shorten cycle times and reduce costs in production management (Haag, p.240). For example, supply chain management software companies have been very successful in developing a B2B marketplace for both large and small companies. Companies realize the cost savings attributed to this type of software. IES, Logistics, SAP, SAS and Ross Enterprises are examples of major supply chain management software companies that have customers from the automotive, retail, computer and health care industries. Hewlett Packard, a major computer company, slashed its transportation budget by $25 \%$ utilizing this type of software. Titleist, a golf industry company, decreased its manufacturing lead times on custom golf balls by more than $50 \%$ from 12 to 5 days (VanScoy, 2001).

\section{Vertical Marketplaces}

A Vertical Marketplace was developed as a business model to enable buyers and sellers in a particular industry to purchase from each other. It also provides an opportunity for information sharing and collaboration on product development. Tables 3 and 4 illustrate the comparison between the traditional industry marketplace and the virtual vertical marketplace. 


\begin{tabular}{|c|c|}
\hline & $\begin{array}{l}\text { TABLE 3: TRADITIONAL BUSINESS2BUSINESS VERTICAL MARKETPLACE TRANSACTION } \\
\text { (TB2BVMT) MODEL }\end{array}$ \\
\hline & Steps in Automotive Company Purchases Parts from Supplier \\
\hline 1. & Company contacts suppliers via email or landline for inventory of parts needed \\
\hline 2. & Supplier can't supply parts. Company looks for other suppliers \\
\hline 3. & Company finally locates suppliers for parts needed. Negotiates pricing. \\
\hline & Steps in Automotive Company Decides to Innovate Automobile Models \\
\hline 1. & Company solicits bid proposals for innovation with deadline submission \\
\hline 2. & Company reviews proposals. \\
\hline 3. & Company selects supplier. Starts collaboration. \\
\hline
\end{tabular}

\begin{tabular}{|ll|}
\hline & TABLE 4: E-COMMERCE B2B VERTICAL MARKETPLACE TRANSACTION (EB2BVMT) MODEL \\
& Steps in Automotive Company Purchases Parts from Supplier/Decides to Innovate Automobile Models \\
1. & Company visits marketplace for appropriate suppliers for parts needed \\
2. & Company sets up virtual meeting to collaborate on potential innovation of models \\
3. & Company solicits proposals in the marketplace for appropriate suppliers \\
4. & Company selects supplier and starts collaboration \\
\hline
\end{tabular}

\section{Business Transaction Analysis}

In Tables 3 and 4, the number of steps for the traditional B2B process is nearly doubled and most likely will take twice as long as the e-commerce business transaction model. The marketplace centralizes the industry's communication and enables companies to more quickly communicate their needs to their suppliers. It also provides a platform for any industry issues. Additionally, it provides a platform for collaboration with other companies to develop new products. It has dramatically impacted the ability for a company to incorporate innovations into their products as well as providing software solutions to many manufacturing issues. Covisint (automotive industry) is a vertical marketplace which represents 266,000 users in 30,000 companies in 96 countries, with 700 applications in seven languages (www.covisint.com). From a business model analysis, this process has streamlined the transaction activities enabling the products to be developed and sold more quickly.

\section{Horizontal Marketplaces}

A Horizontal Marketplace is a virtual marketplace that provides a platform for buyers and sellers in many industries. Most horizontal marketplaces sell products and services necessary for company operations, such as supplies and services. Horizontal marketplaces can also target B2C models as well.

\section{TABLE 5: TRADITIONAL BUSINESS2BUSINESS HORIZONTAL MARKETPLACE TRANSACTION (TB2BHMT)MODEL}

\section{Steps in Company Needs Computers for Company Expansion (Needs are Immediate)}

1. Company researches computer suppliers for best price. Requests information from each supplier. Company opts for bidding process.

2. Company purchasing agent reviews prices. Requests approval from management.

3. Management not satisfied with prices. Request additional information.

4. Agent repeats the steps. Doesn't meet deadline. 


\title{
TABLE 6: E-COMMERCE HORIZONTAL MARKETPLACE TRANSACTION (EB2BHMT) MODEL
}

\author{
Steps in Company Needs Computers for Company Expansion (Needs are Immediate)
}

1. Purchase agent visits several horizontal marketplaces online to obtain pricing information

2. Provides pricing information to management quickly. Management not satisfied with price quotes.

3. Agent quickly secures more information.

4. Management makes decision to order computers. Meets deadline.

\section{Business Transaction Analysis}

Although the traditional method in Table 5 and the virtual method outlined in Table 6 have the same number of steps, the time required for the traditional method of obtaining the information and securing the decision is most likely double or triple the time needed to obtain information from the horizontal marketplace. The development of both the vertical and horizontal marketplaces provides a platform for obtaining needed information quickly for crucial decisions. Again, the e-commerce model utilizes the traditional processes but is more efficient in its transactional processes. These comparisons illustrate the focus of the models on the transactional activities of the models.

\section{BUSINESS2CONSUMER MODEL}

Business to consumer (B2C) refers to all online transactions between companies that sell their products or services for consumers' personal use. A very successful example of an exclusive B2C model is Amazon. Originally, when Amazon started in 1995, management focused on developing the business as the largest online bookstore worldwide. By 1999, Amazon established itself as a one-stop online shopping destination by including video games, home improvement, software and gifts as part of their inventory. Currently, Amazon provides access to millions of different products for their consumers. Amazon continues to improve their customer service by monitoring a customer's buying patterns and developing recommendations for additional purchases (www.amazon.com).

This business model has challenged the way business transactions are performed and how consumers purchase products or services. This model quickly threatened the traditional brick and mortar businesses and has challenged traditional retail operations to include this type of business model in their operations. The traditional retail storefront, which provides a physical location for customers to browse their inventory prior to their purchase, has been replaced by the brick and click e-commerce model which includes an internet website for the retail store. The website enables customers to purchase additional inventory without them visiting the storefront. Since 1996, the percentage of the US population online grew from 14 to $74 \%$ (www.internetworldstats.com). The number of Internet hosts rose to 100 million (Meyer, Davis, 2004). Wal-Mart, JC Penney, Target and other large retailers have established themselves with online presence because their consumers expect them to have websites. In addition to online entrepreneurs, B2C has grown to include services, such as online banking, travel, and real estate sites (Niles, 2007).

\section{TABLE 7: TRADITIONAL BUSINESS2CONSUMER TRANSACTION (TB2CT) MODEL}

\section{Steps in Consumer Goes Shopping to Retail Storefront}

1. Consumer physically enters traditional retail storefront to browse/purchase product

2. Consumer purchases product

3. $\quad$ Consumer uses product

4. If dissatisfied, consumer physically returns to retail storefront to return item

5. Consumer repeats steps 1-3 to find another product from retail storefront 


\begin{tabular}{|ll|}
\hline & \multicolumn{1}{c|}{ TABLE 8: E-COMMERCE BUSINESS2CONSUMER TRANSACTION (EB2CT) MODEL } \\
& \multicolumn{1}{c}{ Steps in Consumer Goes Shopping Online } \\
1. & Consumer visits retail website and browses electronically \\
2. & Consumer purchases product electronically \\
3. & Consumer waits for product delivery \\
4. & If dissatisfied, consumer returns product via mail \\
5. & Consumer repeats steps 1-3 to visit another retail website \\
\hline
\end{tabular}

\section{Business Transaction Analysis}

In Table 7, the steps are similar for the consumer to purchase a product, but more physical effort is made by the consumer to physically purchase a product and if dissatisfied, to physically return the product. Also, transportation is required for this type of search. In Table 8, the process also has five steps, but the time expended is more efficient since the consumer can pursue multiple product searches by visiting several websites simultaneously. The e-commerce model provides for more customer interaction with a business by streamlining the transactional activities. These comparisons emphasize the transactional activities between the seller and buyer.

\section{THE BROKERAGE BUSINESS TRANSACTION MODEL}

The brokerage model brings buyers and sellers together to form a transaction. Brokers play a role in business to business (B2B) and business to consumer (B2C) models. A broker charges a fee for each transaction it facilitates. An auction broker, such as eBay, is an excellent example of a very successful brokerage model (Glasheen, 2004). Tables 7 and 8 outline the different steps taken by a consumer in the traditional brokerage transaction model as compared to the e-commerce brokerage model transaction by the consumer. Although each model has several steps, the e-commerce model maximizes the consumer's time involved in the process by allowing the consumer to participate in multiple auctions simultaneously. This model also allows the business to increase its market share by providing a platform for potentially a million customers to review their auction. Additionally, the consumer doesn't have to leave his house and travel to different auctions to participate in this type of brokerage model. The brokerage model has replaced the more traditional form of auctions.

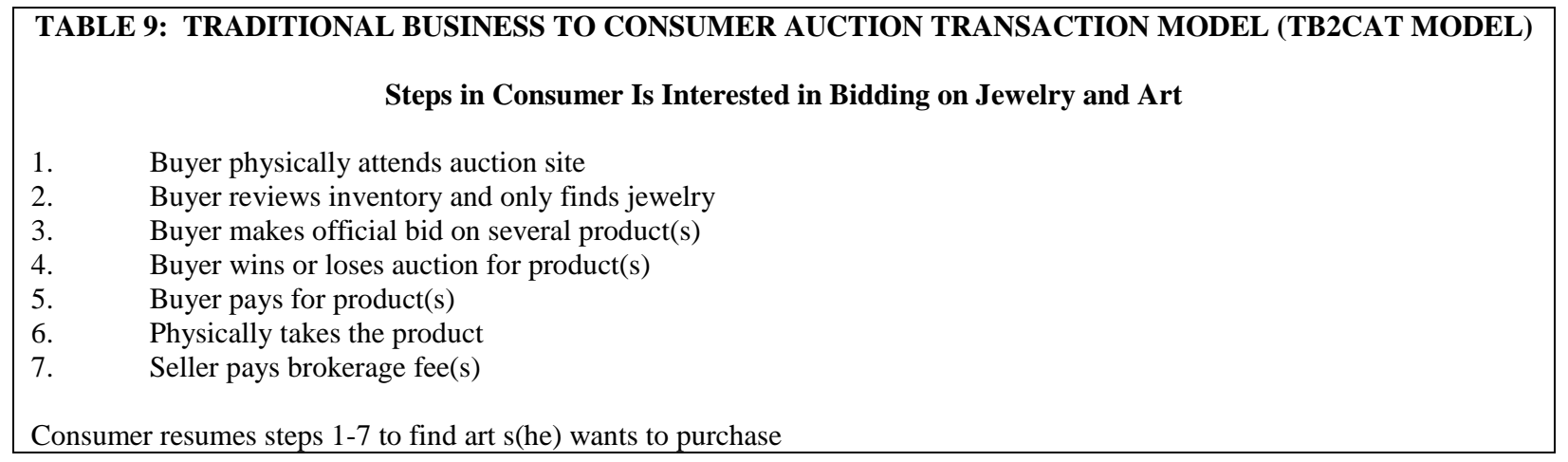




\section{TABLE 10: E-COMMERCE BUSINESS TO CONSUMER AUCTION TRANSACTION (EB2CAT) MODEL}

\section{Steps in Consumer is Interested in Bidding on Jewelry and Art}

1. Buyer visits auction site on computer

2. Buyer searches for specific auctions for both jewelry and art

3. Buyer makes official bids on several products in several auctions

4. Buyer monitors auctions' progress electronically to increase percentage of winning

5. Buyer wins/loses product(s)

6. Buyer pays for products/shipping

7. Buyer receives products via mail

8. Seller pays for brokerage fee(s)

Source: Niles, 2007

\section{Business Transaction Analysis}

The sequence of steps is similar in the traditional business brokerage process outlined in Table 9 and the ecommerce brokerage process outlined in Table 10. However, the new auction process enables a consumer to reduce his time in the auction process as well as enables the consumer to "attend" multiple auctions, which maximizes the consumers' time, exposes him to more products and increases the selling opportunities for the merchant. In the traditional process, the consumer needs to revisit these steps because (s)he could not locate the entire desired inventory at one auction. The e-commerce model maximizes customer satisfaction because it provides several opportunities to purchase a product from many different vendors by streamlining the transactional processes.

\section{Reverse Auction Model}

Another form of the e-commerce brokerage model used in business2business transactions is the reverse auction model. This business process model enables vendors to bid competitively to a company to obtain their business. General Electric Power Systems developed a site specifically for this purpose (Niles, 2007). This reverse auction model reduces the amount of transactions that the business must initiate -- the potential vendors are required to develop bids to obtain GE's business. Say (2000) indicates that this process has saved GE nearly $\$ 150$ million in corporate purchases. Say (2000) indicates that this process has saved GE nearly $\$ 150$ million in corporate purchases (p. 2).

\section{TABLE 11: TRADITIONAL BUSINESS TO BUSINESS REVERSE AUCTION TRANSACTION (TB2BRAT) MODEL}

\section{Steps in Traditional Reverse Auction Transaction Model}

1. Company issues a competitive bid process for services in industry journals

2. Potential vendors subscribe to journal - procurement officers to search for bid requests.

3. Vendors submit bids in accordance to deadlines

4. Business reviews all bids with designated reviewers

5. Business selects vendor for contract

\begin{tabular}{|c|c|}
\hline & TABLE 12: E-COMMERCE REVERSE AUCTION MODEL \\
\hline & Steps in E-Commerce Business to Business Reverse Auction Transaction (eB2BRAT) Model \\
\hline 1. & Business issues a competitive reverse auction notification on website \\
\hline 2. & Any vendor reviews website for reverse auction opportunities \\
\hline 3. & Vendor submits electronically a cost estimate for services prior to deadline \\
\hline 4. & Business reviews all bids and makes decision \\
\hline 5. & Electronically notifies winner of auction \\
\hline
\end{tabular}




\section{Business Transaction Analysis}

In the traditional bidding process outlined in Table 11, the business must allocate time of employees to develop the request for bids that are sent to potential suppliers and published in industry magazines. A deadline is developed for written submissions, which is labor and time intensive. It also limits the number of vendors who could submit bids since the number of suppliers could be restricted by who actually saw the written bid request. As outlined in Table 12, the e-commerce process eliminates a portion of the labor, reduces the deadline for submission, and increases the possibility for more vendors to submit a competitive bid because the business website can be viewed by any interested vendor. The e-commerce model supports a streamlined business transaction model that has normally been time and labor intensive. The model emphasizes the efficiency of the transactional process employed by the model.

\section{CONCLUSION}

This paper has illustrated the lack of agreement on the definition of a business model. Discussed was an abbreviated literature review that emphasizes the different perspectives of a business model. There are categories, such as auction, subscription, or advertising business models (Rappa, 2005). Business models have been defined in the literature as systems with components (Afuah\&Tucci, 2001) or methods to make money (Weill\&Vitale, 2001). They have been categorized as business to business models or business to consumer models (Haag, 2004). Regardless of what type of activity is performed or whether the two parties are either two businesses or a business and a consumer, the focus of a business model is its transactional activities.

This author has focused on the transactional activities between the buyer and seller, regardless of whether it is a traditional transaction or an electronic transaction. This paper has provided six comparisons of the differences between a traditional transaction between the buyer and the seller and the electronic transaction between the buyer and the seller. The direct comparisons of traditional and e-commerce business models illustrate the major component of a business model -- the transaction that occurs between the seller and buyer. This concept of a business model also illustrates that the electronic transaction model often is less labor and time intensive that will enable a business to increase their profit margin for each of their transactions. Therefore, the author's definition of a business model is 'the traditional or electronic transactional activities between a buyer and a seller that result in an exchange'. This new definition of a business model will enable managers to asses transactions of their business models to determine their efficacy, which will ultimately impact their profit margin.

\section{AUTHOR INFORMATION}

Nancy J. Niles recently joined the AACSB accredited Department of Business Administration at Lander University in Greenwood, South Carolina. She teaches business and health care management. She previously taught at Concord University in Athens, West Virginia for four years. She spent nearly 20 years in management before joining the academe. Her research interests include business models, business ethics and health care management. She received her PhD from the University of Illinois at Urbana Champaign in 1992 and her Master of Public Health from Tulane University. She is currently working on a dual MS/MBA degree from the University of Maryland.

\section{REFERENCES}

1. Afuah, A. \&Tucci, C. (2001). Internet business models and strategies. New York: McGraw-Hill Irwin.

2. http://www.amazon.com (Accessed April 22 $\left.{ }^{\text {nd }}, 2008\right)$.

3. $\quad$ http://www.covisint.com (Accessed August 16 ${ }^{\text {th }}, 2008$ )

4. Davis, M.M. \& Heineke, J. (2005) Operations management: Integrating Manufacturing and Services. New Jersey: McGraw-Hill Irwin.

5. Drucker, P.F. (October 1999). Beyond the information revolution. Atlantic Monthly: 47-57.

6. Glasheen, C., Gantz, J.F., Emberly, D. Worldwide Internet Usage and Commerce 2004- 2007 Forecast: Internet Commerce Market Model-Version 9.1. Retrieved June $2^{\text {nd }}, 2005$ from http://idc.com 
7. Haag, S., Cummings, M., \& McCubbrey, D.J (2005). Management Information Systems. New Jersey:McGraw-Hill Irwin.

8. Hansen, F. (2003). Global e-commerce growth. Business Credit, 105.9:3.

9. Hawkins, R. (2002). The phantom of the marketplace: searching for new e-commerce Business models. Euro CPR 2002. Barcelona.

10. www.internetworldstats.com/stats.htm (Accessed August 15 $5^{\text {th }}, 2008$ ).

11. Www.ism.ws/ (Accessed April 20 $\left.{ }^{\text {th }}, 2008\right)$.

12. Kenn, P, Qureshi, S (2006). Organizational transformation through business models: A framework for business model design. Proceedings of the $39^{\text {th }}$ Hawaii International Conference on System Sciences 2006.

13. Lambert, S. (2006). Do we need a "real" taxonomy of e-business models? School of Commerce Research Paper Series: 06-6. ISSN: 1441-3906.

14. Lambert, S. (2006). A business model research scheme. $19^{\text {th }}$ Bled Conference, Slovenia. June 5-7, 2006.

15. Larson, P. (March 16, 2000). A short intro to business to business e-commerce. Retrieved September 20, 2005 from http://www.fool.com.

16. Mahadevan, B. (2000). Business models for internet based e-commerce an anatomy. California Management Review, 42(4): 1-4.

17. Niles, N. (2007). Chapter in Textbook: Creative destruction on steroids. Rediscovering Schumpeter:

18. Creative Destruction Perspective in Creating, Inventing, Innovating, Diffusion and Impact. New York: Palgrave/Macmillan.

19. Meyer, C., Davis, S. All volatility: all the time - chapter 1, learning from life cycles (2005, May 25). Retrieved June 15, 2007 from http://www.businessweek.com.

20. http://www.napm.org (Accessed April 30th, 2008).

21. Porter, M.E. (2001). Strategy and the internet. Harvard Business Review, 79(2): 63-78.

22. Rappa, M. (2005, September 20). Business models on the web. Retrieved September 20, 2006 from http://www.digitalenterprise.org/models/models/html.

23. Rao,S., Metts, G., Monge, C.A. (2003) Electronic commerce in small and medium sized enterprises: A stage model and its implications. Business Process Management Model 9(1):11-32.

24. Say, P. (2000, August 20). The B2B primer. Retrieved September 21, 2007 from http://www.clickz.com.

25. Timmers, P. (1999). Electronic commerce strategies and models for business to business trading. Chichester: Wiley\&Sons.

26. VanScoy, K. (December 2001). Recession-proof your business. Small Business: 84-88.

27. Weill, P\& Vitale (2002). What IT infrastructure capabilities are needed to implement e-business models. MIS Quarterly Executive 1(1):17-34. 
NOTES 